\title{
Biobased Cationically Polymerizable Epoxy Thermosets from Furan and Fatty Acid
} Derivatives

\author{
Nameer, Samer; Larsen, Daniel B.; Duus, Jens Ø.; Daugaard, Anders E.; Johansson, Mats
}

Published in:

A C S Sustainable Chemistry \& Engineering

Link to article, DOI:

10.1021/acssuschemeng.8b01817

Publication date:

2018

Document Version

Peer reviewed version

Link back to DTU Orbit

Citation (APA):

Nameer, S., Larsen, D. B., Duus, J. Ø., Daugaard, A. E., \& Johansson, M. (2018). Biobased Cationically Polymerizable Epoxy Thermosets from Furan and Fatty Acid Derivatives. A C S Sustainable Chemistry \& Engineering, 6(7), 9442-9450. https://doi.org/10.1021/acssuschemeng.8b01817

\section{General rights}

Copyright and moral rights for the publications made accessible in the public portal are retained by the authors and/or other copyright owners and it is a condition of accessing publications that users recognise and abide by the legal requirements associated with these rights.

- Users may download and print one copy of any publication from the public portal for the purpose of private study or research.

- You may not further distribute the material or use it for any profit-making activity or commercial gain

- You may freely distribute the URL identifying the publication in the public portal 
This document is confidential and is proprietary to the American Chemical Society and its authors. Do not copy or disclose without written permission. If you have received this item in error, notify the sender and delete all copies.

\section{Bio-based cationically polymerizable epoxy thermosets from furan and fatty acid derivatives}

\begin{tabular}{|c|c|}
\hline Journal: & ACS Sustainable Chemistry \& Engineering \\
\hline Manuscript ID & sc-2018-01817u.R1 \\
\hline Manuscript Type: & Article \\
\hline Date Submitted by the Author: & 25-May-2018 \\
\hline Complete List of Authors: & $\begin{array}{l}\text { Nameer, Samer; KTH Royal Institute of Technology, Fibre and Polymer } \\
\text { Technology, Division of Coating Technology } \\
\text { Larsen, Daniel; Danmarks Tekniske Universitet, Department of Chemistry } \\
\text { Duus, Jens; Technical University of Denmark, Chemistry } \\
\text { Daugaard, Anders; Technical University of Denmark, Chemical Engineering } \\
\text { Johansson, Mats; KTH Royal Institute of Technology, Fibre and Polymer } \\
\text { Technology, Division of Coating Technology }\end{array}$ \\
\hline
\end{tabular}

\section{SCHOLARONE}

Manuscripts 


\title{
Bio-based cationically polymerizable epoxy thermosets from furan and fatty acid derivatives
}

\author{
Samer Nameer $^{\dagger 1}$, Daniel B. Larsen ${ }^{\dagger 2,3}$, Jens Ø. Duus ${ }^{3}$, Anders E. Daugaard ${ }^{2}$, Mats Johansson*1 \\ ${ }^{1}$ KTH Royal Institute of Technology, Department of Fibre and Polymer Technology, Division of \\ Coating Technology, SE-100 44 Stockholm, Sweden. \\ ${ }^{2}$ Danish Polymer Centre (DPC), Department of Chemical and Biochemical Engineering, Technical \\ University of Denmark, Søltofts Plads Building 227, 2800 Kgs. Lyngby, Denmark. \\ ${ }^{3}$ Department of Chemistry, Technical University of Denmark, Kemitorvet, Bygning 207, 2800 Kgs. \\ Lyngby, Denmark. \\ $\uparrow$ These authors contributed equally to the work. \\ *Correspondence to: Mats Johansson (E-mail: matskg@kth.se)
}

\section{Keywords:}

Renewable; epoxy; FDCA; UV; thermoset

\begin{abstract}
In the pursuit of environmentally friendly building blocks in polymer chemistry the utilization of bio-based monomers is highly desired. In the present study has the bio-based monomer 2,5furandicarboxylic acid (FDCA) been extended into epoxy thermosets. The study presents the synthesis of diallyl furan-2,5-dicarboxylate (DAFDC) followed by an epoxidation of the allyls to form diglycidyl furan-2,5-dicarboxylate (DGFDC). DGFDC was then co-polymerized in both stoichiometric and off-stoichiometric ratios with epoxidized fatty methyl esters to form a range of thermosets. The cross-linking reaction was either thermally or UV-induced cationic polymerization utilizing onium salt initiators where the reactivity was studied by DSC and real-time FTIR. Furthermore, the structure-property relationships of the final thermosets were determined by DMTA revealing a possibility to tune the properties over a wide range. In addition thermosets were made from diglycidyl Bisphenol-A (DGEBA) with epoxidized fatty methyl esters made for comparative purposes.
\end{abstract}




\section{Introduction}

The inevitable exhaustion of fossil resources leads to a necessity for development of bio-based alternatives to previously petrol-based industries. An example of this is the plastics industry, where the most widely used commodity plastics have been oil-based. ${ }^{1}$ In addition, the discussion of depleting fossil oil reserves together with environmentally hazardous emissions of gases has caused the need for development of an array of new environmentally benign routes towards bio-based monomers and polymers. With a vast amount of different bio-feedstocks becoming available from bio-refineries, ${ }^{2}$ the development of new methods for the utilization of these are highly desired.

An interesting source of bio-based raw materials is fatty acids due to their abundance, low cost and versatility. ${ }^{3}$ Fatty acids are available both from annual crops, e.g. vegetable oils, or conifers, e.g. tall oil fatty acid, in a wide variety with the common feature that they contain an acyl group and a long hydrocarbon chain. Furthermore, many fatty acids have additional functionalities such as alkenes, hydroxyls, or epoxides. ${ }^{4,5}$ One example of plant oil utilized for material applications is linseed oil (LO) used for alkyd paints already developed in the 1920s. ${ }^{6,7}$ LO is a triglyceride composed of glycerol and fatty acids with a high average number of unsaturations in $\mathrm{C}_{18}$ fatty acids. ${ }^{4,5}$ From a chemist point of view LO is highly interesting due to its intrinsic functionalities. The unsaturations can either be used directly in an oxidative radical polymerization e.g. autoxidation ${ }^{8}$ or be oxidized by a peracid to form an epoxide. ${ }^{9}$ Epoxidized vegetable oils are already established in several applications such as printing inks, e.g. epoxidized soy bean oil. These resins are however limited to applications without high demands on the mechanical performance. ${ }^{5}$ Several routes to overcome this issue have been tested and amongst the most successful is the combination of epoxidized fatty acids with sucrose as a rigid component in fatty acid sucrose esters. ${ }^{10,11}$ In addition, epoxyfunctional fatty acids are also found directly as synthesized in natural systems e.g. vernolic acid in Vernonia $_{\text {species }}{ }^{12}$ and Euphorbia lagascae ${ }^{13}$ or cis-9,10-epoxy-18-hydroxyoctadecanoic acid in birch bark ${ }^{14}$ (betula pendula), leaf $\operatorname{cutin}^{15}$ (camelina) and in tea leaves ${ }^{16}$ (camellia sinensis).

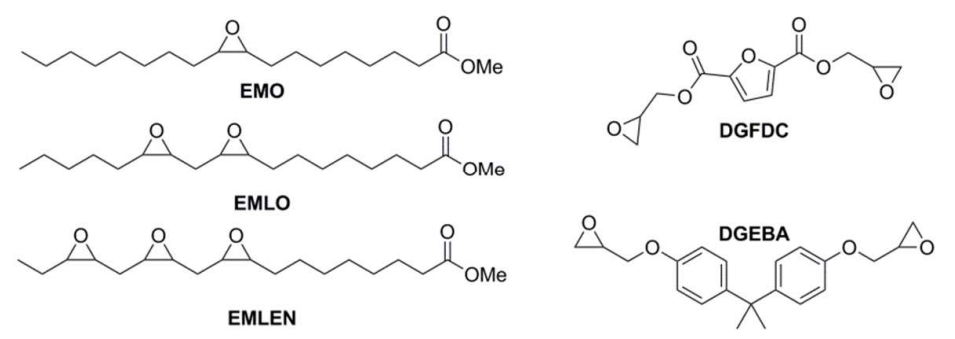

Figure 1: Chemical structures of the monomers used 
Another type of monomer which has received great attention through the latest years is the biobased 2,5-furandicarboxylic acid (FDCA), which can be produced from sugars with hydroxyl methylfurfural (HMF) as an intermediate. ${ }^{3,17,18}$ The reason for the attention is due to that FDCA share similar properties with the petrol-based terephthalic acid, ${ }^{19}$ produced from xylene, which finds broad application in the polymer industry. ${ }^{20}$ Terephthalic acid constitutes the major building block of poly ethylene terephthalate (PET), the plastic used for the production of plastic bottles, food containers as well as fibers in cloth fiber applications. In addition, FDCA is one of the twelve building block chemicals that is considered to be a platform for synthesis of high-value bio-based chemicals or materials. ${ }^{2}$ FDCA has not only been considered as a building block for thermoplastics such as PET but also as a building block in various other polyesters used for thermosets. ${ }^{18}$ Moreover, FDCA has been functionalized with allyl groups using allyl alcohol ${ }^{21}$ or allyl bromide $^{22}$ which in turn would pave the way for FDCA to be used in thiol-ene thermosets ${ }^{21}$ and as epoxy monomers in $2 \mathrm{~K}$-systems ${ }^{22}$. The production of FDCA has also recently been scaled up and is now available in larger quantities on the market by companies e.g. BASF, Avantium and Corbion.

One specific type of functionality that has obtained increased attention in the development of new bio-based polymer systems is the epoxide group. ${ }^{5}$ The epoxy functional group has a suitable reactivity due to its ring-strain it is a versatile functionality for a wide range of chemical transformations. The epoxide opening can be catalyzed under both basic and acidic conditions hence, providing a unique platform for different types of reactions. ${ }^{23}$ Epoxide chemistry is also well established in numerous applications ranging from surface (protective) coatings, electronics, inks, adhesive, to composites just to mention a few. Commonly used epoxy resins in thermosetting applications are the diglycidyl ether of bisphenol-A (DGEBA) and the cycloaliphatic epoxy resin 3,4-epoxycyclohexylmethyl-3',4'-epoxycyclohexanecarboxylate (ECC). ${ }^{24,25}$ They have both been studied in thermal or radiation induced curing reactions. The main advantage of using them are predominantly due to their inherent ring structures which provide thermal stability i.e. high glass transition temperature $(\mathrm{Tg})$ to the final thermoset. However, they are derived from fossil fuels hence, considered environmentally less benign. ${ }^{26}$ 

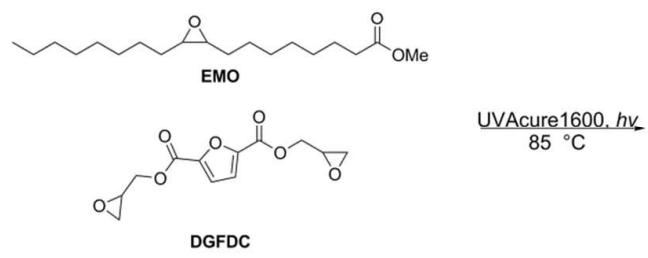

Scheme 1: Schematic illustration of the reaction between EMO and DGFDC forming a cross-linked thermoset.

Since the ground breaking work by Crivello and $\mathrm{Lam}^{27,28}$ in the synthesis of diaryliodonium and triarylsulfonium salts, cationic polymerization of epoxides has gained popularity in both academia and industry. ${ }^{29}$ Today cationic polymerization is a commonly used synthetic route for polymer thermosets through cyclic ether monomers. The reaction follows a chain-growth mechanism and can be triggered by e.g. UV light or temperature. In addition, cationic polymerization is considered oxygen insensitive, fast, and has an inherent low shrinkage of the final material. ${ }^{30}$ Triggered photochemically or thermally, the initiator (a diaryliodonium or triarylsulfonium salt) dissociates to form a strong acid that protonates the epoxy-ring which then leads to an event of chain-growth propagation via the activated epoxy-ring. ${ }^{31}$ A key feature is that the counter ion needs to be nonnucleophilic, which is the case for the most commonly used counter ions e.g. $\mathrm{PF}_{6}{ }^{-}$and $\mathrm{SbF}_{6}{ }^{-}$. Most utilized epoxides in commercial systems are either glycidyl ethers, cycloaliphatic, or 1,2disubstituted aliphatic epoxides.

In this paper we expand the scope of FDCA-based monomers by using the diglycidyl ester of FDCA, diglycidyl furan-2,5-dicarboxylate (DGFDC) as a rigid monomer structure in combination with the aforementioned epoxidized fatty esters, from here on denoted EMX (Figure 1), in order to produce new types of bio-based epoxy resins. The study also reveals details on the intrinsic reactivities of the involved epoxides both by themselves and in co-polymerization reactions revealing intrinsically different reactivity of glycidyl esters compared to more conventional epoxides. It is demonstrated that both the final thermoset properties as well as the curing performance can be adapted by a proper choice of monomer mixtures. 


\section{Experimental}

\section{Materials}

2,5-furandicarboxylic acid (FDCA) (97\%), allyl alcohol ( $\geq 99 \%)$, 3-Chloroperbenzoic acid (mCPBA) ( $\leq 77 \%)$, acetone (HPLC grade, $99.8 \%$ ), and sulphuric acid $\left(\mathrm{H}_{2} \mathrm{SO}_{4}\right)(95-97 \%)$ were purchased from Sigma Aldrich. Epoxidized linseed oil (ELO) was provided by Ackros Chemicals. The photoinitiator UVAcure 1600 was supplied by CYTEC. All materials were used as received, unless otherwise noticed

\section{Analytical methods}

\section{Nuclear Magnetic Resonance Spectroscopy (NMR)}

In order to obtain ${ }^{1} \mathrm{H}-\mathrm{NMR}$ a Bruker spectrometer (400 MHz) was used. The data for ${ }^{1} \mathrm{H}-\mathrm{NMR}$ and ${ }^{13} \mathrm{C}$-NMR were acquired by using 16-32 scans and 512 scans respectively and with 1 second relaxation time. Deuterated chloroform $\left(\mathrm{CDCl}_{3}\right)$ containing tetramethylsilane (TMS) and DMSO-d6 were used to dissolve the samples. The residual solvent peaks were used as reference $\left(\mathrm{CDCl}_{3}: 7.26\right.$ ppm ( $\left.{ }^{1} \mathrm{H}-\mathrm{NMR}\right)$ and $77.16 \mathrm{ppm}\left({ }^{13} \mathrm{C}-\mathrm{NMR}\right)$ and DMSO-d6: $2.50 \mathrm{ppm}\left({ }^{1} \mathrm{H}-\mathrm{NMR}\right)$ and $39.52 \mathrm{ppm}$ $\left({ }^{13} \mathrm{C}-\mathrm{NMR}\right)$. The acquired spectra were analyzed using MestReNova v9.0.0-12821 (Mestrelab Research S.L. 2013).

\section{Fourier-Transform Infrared Spectroscopy (FTIR) and Real-Time FTIR (RT-FTIR)}

FTIR and RT-FTIR were recorded on a Perkin-Elmer Spectrum 100 equipped with a triglycine sulphate (TGS) detector. The instrument was equipped with a single reflection (ATR: attenuated total reflection) accessory unit Golden gate from Graseby Specac LTD (Kent, England). The Golden gate was equipped with a temperature control (Specac, Heated Golden Gate Controller). The FTIR spectra were recorded using 8 scans with a $4.0 \mathrm{~cm}^{-1}$ resolution and a range from 600 $4000 \mathrm{~cm}^{-1}$. The data was analyzed using Spectrum software v. 10.5.1 from Perkin-Elmer. For RTFTIR the data were recorded at 1 scan per 5.7 seconds with a resolution of $4.0 \mathrm{~cm}^{-1}$. The software used for RT-FTIR was TimeBase ${ }^{\circledR}$ from Perkin-Elmer. The results from the RT-FTIR experiments were evaluated from conversion towards end of the reaction i.e. when changes in the spectra occurred, why the traces can be seen as comparative rates between the different reactions. Absolute values of epoxy conversion could not be obtained due overlapping peaks. The conversion was calculated as the relative change between the initial and final states of the curing reaction i.e. setting the initial state to 0 and the final state to 1 . For comparative purposes the point in time for $95 \%$ conversion and maximum rate (in $\% / \mathrm{s}$ ) was determined at the maximal slope throughout the 
reaction. Initiation time was estimated from the tangent at the steepest slope, with the initiation time being determined as the intersection of the tangent with the $\mathrm{x}$-axis

\section{Differential Scanning Calorimetry (DSC)}

The thermal analyses were obtained by a Mettler Toledo DSC-1 equipped with Gas Controller GC100. Approx. 5-10 mg of sample was weighed into $100 \mu \mathrm{L}$ aluminum crucible. The data were collected using heating/cooling cycles from $30{ }^{\circ} \mathrm{C}$ to $300{ }^{\circ} \mathrm{C}$ for DSC kinetics and -50 to $200{ }^{\circ} \mathrm{C}$ for the Tg of the EMX:DGFDC/DGEBA thermosets. The temperature gradient rate was set to $10{ }^{\circ} \mathrm{C}$ $\min ^{-1}$ with $5 \mathrm{~min}$ of isotherms at the highest/lowest temperature value for all DSC measurements. The analyses were carried out in inert atmosphere using $10 \mathrm{~mL}$ of $\mathrm{N}_{2}$ gas. The $\mathrm{Tg}$ was obtained from the second heating cycle and was reported as the midpoint value of the heat capacity change. Determination of kinetic parameters from DSC scans were achieved using Borchardt and Daniels kinetics $^{32,33}$ in which the reaction rates, constants and orders are determined from the enthalpy obtained by integration of the reaction peak from a single DSC run. The Borchardt and Daniels method utilizes equation (1)-(3) in order to construct an Arrhenius plot. For these equation $\alpha$ is the fractional conversion, $\Delta H$ is the total enthalpy for the reaction, $\Delta H_{T}$ is the enthalpy of the reaction left to proceed at time, $\mathrm{t}, \mathrm{n}$ is the reaction order and $\mathrm{K}(\mathrm{T})$ is the temperature dependent rate constant. The data points for these calculations are obtained by dividing the integral of the DSC exothermal reaction peak into 20 evenly spaced areas from the temperature at $10 \%$ of the peak height until 50 $\%$ of the reaction has occurred (at $\Delta H_{T}=0.5$ ). This limitation was introduced in order to circumvent the decrease in reaction rate from the increase in cross-linking density.

$$
\begin{gathered}
1-\alpha=\Delta H_{T} / \Delta H \\
\frac{d \alpha}{d t}=\frac{d H}{d t} / \Delta H \\
\ln \frac{d \alpha}{d t}=\ln (K(T))+n * \ln (1-\alpha)
\end{gathered}
$$

\section{Dynamical Mechanical Thermal Analysis (DMTA)}

DMTA was conducted to obtain the physical properties of the synthesized thermosets. A Q800 DMTA (TA instruments was used. The instrument was equipped with a clamp for tensile testing. The data were collected using a temperature ramp from $-50{ }^{\circ} \mathrm{C}$ to $200{ }^{\circ} \mathrm{C}$ using a heating rate of 3 ${ }^{\circ} \mathrm{C} \min ^{-1}$. The frequency was set to $1 \mathrm{~Hz}$. The $\mathrm{Tg}$ of each sample was obtained from the maximum of the $\tan \delta$ peak. 


\section{UV-light source}

The UV-light was generated from a Hamamatsu L5662 with a standard medium-pressure $200 \mathrm{~W}$ L6722-01 Hg-Xe lamp. The intensity of the UV-light was measured by a Hamamatsu power meter (model C6080-03) calibrated for $365 \mathrm{~nm}$. The intensity was measured to $80-90 \mathrm{~mW} \mathrm{~cm} \mathrm{~cm}^{-2}$ for all UV-curing reactions in this study.

\section{Automated column purification}

The fatty acid methyl esters were separated by Isolera 4 advanced automated flash purification from Biotage equipped with UV detector. A $50 \mathrm{~g} \mathrm{KP-Sil} \mathrm{column} \mathrm{packed} \mathrm{with} \mathrm{silica} \mathrm{was} \mathrm{used} \mathrm{to} \mathrm{separate}$ the FAME mixture. The column was packed with approx. $10 \mathrm{wt}$. \% of sample relative to the weight amount of silica in the column

\section{Synthesis procedures and polymerization procedures}

\section{Synthesis of diallyl furan-2,5-dicarboxylate (DAFDC)}

Following literature procedure, ${ }^{21}$ FDCA $(50.0 \mathrm{~g}, 0.32 \mathrm{~mol})$ was added allyl alcohol $(500 \mathrm{~mL})$ and concentrated $\mathrm{H}_{2} \mathrm{SO}_{4}(1 \mathrm{~mL})$. The suspension was heated to $115^{\circ} \mathrm{C}$ (mildly refluxing) for 72 hours. The obtained solution was cooled to room temperature and the reaction mixture was concentrated until almost fully dry, yielding a black residue, which was diluted with diethyl ether $(500 \mathrm{~mL})$, and washed twice with a saturated sodium bicarbonate solution $(1000 \mathrm{~mL}$ in total). The organic phase was concentrated yielding a yellow solid, which upon distillation (b.p. $140{ }^{\circ} \mathrm{C}$ at $15 \mathrm{mbar}$. Corrected b.p. $\left.276^{\circ} \mathrm{C}\right)$ yielded diallyl furan-2,5-dicarboxylate $(56.2 \mathrm{~g}, 74.2 \%) .{ }^{1} \mathbf{H}$ NMR (400 MHz, DMSOd6) $\delta: 7.47(\mathrm{~d}, \mathrm{~J}=2.3 \mathrm{~Hz}, 1 \mathrm{H}), 6.02(\mathrm{ddt}, \mathrm{J}=17.4,10.7,5.5 \mathrm{~Hz}, 1 \mathrm{H}), 5.45-5.25(\mathrm{~m}, 2 \mathrm{H}), 4.82$ (dt, $\mathrm{J}=5.6,1.4 \mathrm{~Hz}, 2 \mathrm{H}) .{ }^{13} \mathrm{C}$ NMR (101 MHz, DMSO-d6) $\delta:$ 157.0, 146.0, 132.0, 119.3, 118.7, 65.6.

\section{Synthesis of diglycidyl furan-2,5dicarboxylate (DGFDC)}

Following modified literature procedure, ${ }^{22}$ DAFDC (4.98 g, $\left.21.08 \mathrm{mmol}\right)$ and m-CPBA (77 wt. \% pure, $11.84 \mathrm{~g}, 52.83 \mathrm{mmol})$ was suspended in dichloromethane $(40 \mathrm{~mL})$ and heated to $40{ }^{\circ} \mathrm{C}$ for 72 hours. The resulting suspension was filtered and rinsed with dichloromethane $(30 \mathrm{~mL})$. The organic phase was washed with a $10 \%$ aqueous solution of $\mathrm{Na}_{2} \mathrm{SO}_{4}(50 \mathrm{~mL})$, followed by a $10 \%$ aqueous solution of $\mathrm{Na}_{2} \mathrm{CO}_{3}(50 \mathrm{~mL})$ and lastly demineralized water $(50 \mathrm{~mL})$. The organic phase was dried with $\mathrm{MgSO}_{4}$ and concentrated to yield diglycidyl furan-2,5-dicarboxylate (DGFDC) (5.11 g, 90.0 \%) as a white crystalline solid. ${ }^{1} \mathbf{H}-\mathbf{N M R}(400 \mathrm{MHz}, \mathrm{DMSO}-\mathrm{d} 6) \delta 7.49$ (s, 2H), 4.68 (dd, J = 12.4, $2.7 \mathrm{~Hz}, 2 \mathrm{H}), 4.10(\mathrm{dd}, \mathrm{J}=12.3,6.6 \mathrm{~Hz}, 2 \mathrm{H}), 3.33(\mathrm{~d}, \mathrm{~J}=4.8 \mathrm{~Hz}, 2 \mathrm{H}), 2.84$ (t, J = 4.6 Hz, 2H), 2.73 
$(\mathrm{dd}, \mathrm{J}=5.0,2.6 \mathrm{~Hz}, 2 \mathrm{H}) .{ }^{13} \mathrm{C}-\mathbf{N M R}(101 \mathrm{MHz}, \mathrm{DMSO}-\mathrm{d} 6) \delta$ 157.06, 145.91, 119.51, 66.03, 48.80, 43.90 .

\section{Transesterification of Epoxidized Linseed Oil (ELO)}

Following literature procedure ${ }^{34}$ the different fatty acid methyl esters EMO, EMLO and EMLEN were retrieved by methanolysis procedure. ELO (20 g) was weighed into a round bottom flask equipped with a magnetic stirrer. To the round bottom flask was $\mathrm{NaOH}$ dissolved in methanol $(0.02$ $\mathrm{M}, 250 \mathrm{~mL}$ ) added under stirring. The round bottom flask was then equipped with a condenser and was then heated to $68^{\circ} \mathrm{C}$ for 1 hour. The reaction mixture was then cooled to room temperature and the fatty acids were extracted in n-heptane to remove the glycerol. The n-heptane was rotary evaporated resulting in a fatty acid mixture (15 g, $75 \%$ ). Automated column chromatography (Isolera 4) was then used to separate the different monomers. Silica was used as a stationary phase and a gradient of n-heptane:ethyl acetate as mobile phase. The pure fractions of each monomer were collected and the solvents were rotary evaporated. To completely dry the monomers from residual solvent the monomers were put in vacuum oven at $50{ }^{\circ} \mathrm{C}$ overnight. The pure monomers EMO $(2 \mathrm{~g}$, $10 \%)$, EMLO (2 g, $10 \%$ ) and EMLEN (5 g, $25 \%)$ were then stored in glass vials at room. temperature. ${ }^{1} \mathrm{H}-\mathrm{NMR}$ and ${ }^{13} \mathrm{C}-\mathrm{NMR}$ (Figure S5-10) and FTIR (Figure S12) of the monomers can be found in supporting information.

\section{General procedure for photo-curing followed by RT-FTIR}

The desired amounts of DGFDC and EMX monomers (see Table 1 for monomer ratios) were added to in a small vial and dissolved using a $10 \mathrm{mg} \mathrm{mL}^{-1}$ solution of UVAcure 1600 in acetone, resulting in a dry mixture containing 2 wt. \% UVAcure 1600. For high DGFDC ratios, additional acetone was required for a fully homogenous solution, and the amount of acetone was doubled in these cases. The crystal located on the Golden gate accessory unit was preheated to $85{ }^{\circ} \mathrm{C}$ and a background scan was recorded before a $10 \mu \mathrm{L}$ of the solution (or $20 \mu \mathrm{L}$ for samples containing additional acetone) was applied to the crystal. The mixture was left at $85{ }^{\circ} \mathrm{C}$ for two minutes for all acetone to evaporate. This was followed by irradiation with UV-light and RT-FTIR measurements for 30 minutes for EMO and EMLO systems and 60 min for EMLEN system and pure DGFDC.

\section{General procedure for curing of films for DMTA}

The desired amounts of DGFDC or DGEBA and EMX monomers were weighed in a vial with a magnetic stir bar and UVAcure 1600 was added amounting to $2 \mathrm{wt}$. \% of the total monomer weight. The vial was closed and heated to $85^{\circ} \mathrm{C}$ in an oil bath while stirring, yielding a homogenous liquid. 
The hot solution was added to a silicone mold which already was preheated using a heating plate set at $100{ }^{\circ} \mathrm{C}$. The sample was irradiated with UV-light at this temperature for one hour resulting in fully cured films usable for DMTA measurements. The resulting dimensions of the prepared films were $20-30 \mathrm{~mm}$ in length, $0.2-0.3 \mathrm{~mm}$ in thickness and $4-5 \mathrm{~mm}$ in width.

\section{Results and Discussions}

\section{Synthesis of monomers}

The DGFDC monomer was synthesized using a green esterification of FDCA and allyl alcohol using a catalytic amount of sulfuric acid, forming diallyl furan-2,5-dicarboxylate as shown in previous works, ${ }^{21}$ followed by epoxidation with m-CPBA in high yield as illustrated in Scheme 2. The synthesis procedure was confirmed both by NMR (Figure S1-4) and FTIR (Figure S11). The obtained DGFDC was white crystalline solid with a melting point of $83{ }^{\circ} \mathrm{C}$ confirmed by DSC (Figure S22).

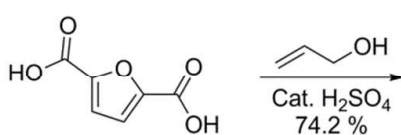

$74.2 \%$

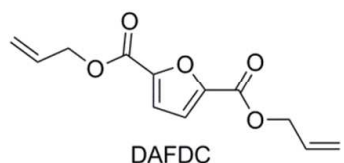

DAFDC

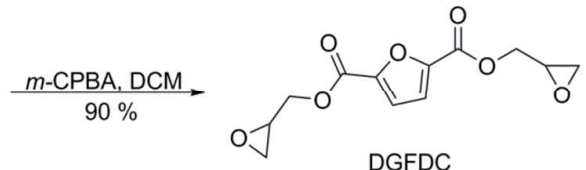

DGFDC

Scheme 2: Synthesis of DAFDC and DGFDC monomers

This synthesis route was chosen over the alternative route using epichlorohydrin ${ }^{35,36}$ to allow welldefined and pure monomers to be made which in turn allow for a more detailed structure-property relationship to be determined.

\section{Curing performance}

In order to evaluate the activation energies of the utilized monomers reactive DSC runs of all systems were carried out using the intended UV-initiator as a thermal initiator. Because this type of activation requires higher amount of energy compared to UV-initiation the absolute activation energies obtained are unrepresentative of the UV-initiated system. However, assuming thermal activation follows the same polymerization mechanism the relative activation energies would be comparable to those of the UV-initiated system. For this setup the pure monomers were run in a DSC scan with 2 wt. \% of UVAcure 1600, yielding an exothermal curing peak (Figure 2A), which upon integration gives the enthalpy of the curing reaction. Using Borchardt and Daniels kinetics it is hereby possible to obtain activation energies for the monomers. This type of kinetic calculation could not be applied to the tri-functional epoxide EMLEN due to multiple curing peaks as a result 
of the different reactivity of the epoxides. However, activation energies were obtained for DGFDC, EMO and EMLO, showing much lower activation energies for the fatty-acid based epoxides. The relative activation energies being 1.00, 1.09 and 2.00 for EMO, EMLO and DGFDC respectively. Details on these calculations, including Arrhenius plots and reaction order refinements are available in the supporting information (Figure S13-25).
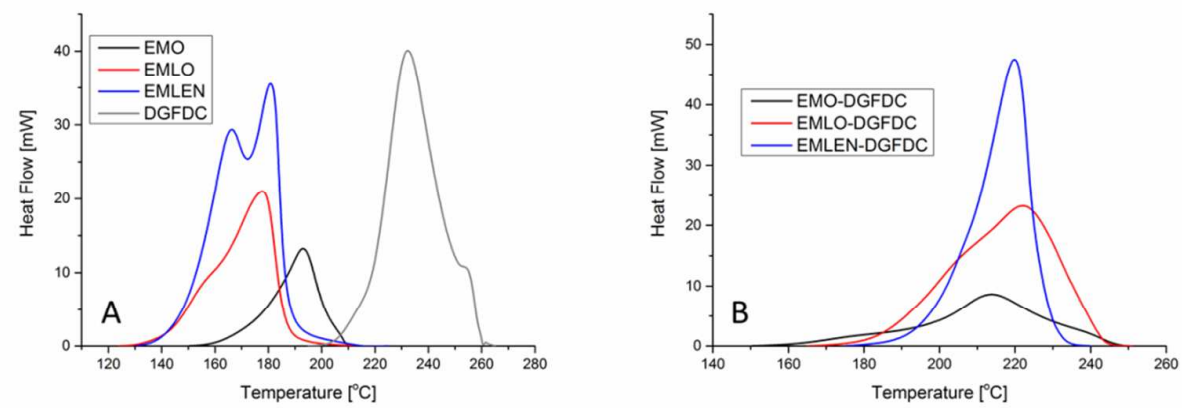

Figure 2: Reactive DSC thermograms of A: pure monomers EMO, EMLO, EMLEN and DGFDC; and B: mixtures of 1:1 epoxy molar ratio of EMO:DGFDC, EMLO:DGFDC and EMLEN:DGFDC. In both A and B the reactions were thermally initiated by using UVAcure 1600.

Furthermore, reactive DSC runs of the reactive mixtures were used to investigate the copolymerization of DGFDC and EMX monomers. The monomers were mixed using a 1:1 epoxy molar ratio and 2 wt. \% UVAcure 1600 was added as initiator. The DSC thermograms showed a combined curing peak much below the curing temperature of pure DGFDC. Even though the curing reactions were occurring simultaneously the observed peaks did not show as a bell-shaped curve making the Borchardt and Daniels kinetics method inadequate for determining kinetic parameters for the combined reaction. The curing peaks for the three mixed EMX-DGFDC systems are shown in Figure 2B. Though kinetic parameters for these reactions could not be estimated with Borchardt and Daniels kinetics the combined peaks did however show that co-polymerization of the DGFDC and EMX monomers takes place with the reaction occurring at lower temperatures compared to pure DGFDC.

All EMX-DGFDC UV-curing reactions were followed using RT-FTIR, allowing close following of the disappearance of epoxy peaks $\left(820-900 \mathrm{~cm}^{-1}\right)$ as well as the formation of ether bonds $(1050-$ $1100 \mathrm{~cm}^{-1}$ ). The conversions of the various systems are presented in Figure 3. 

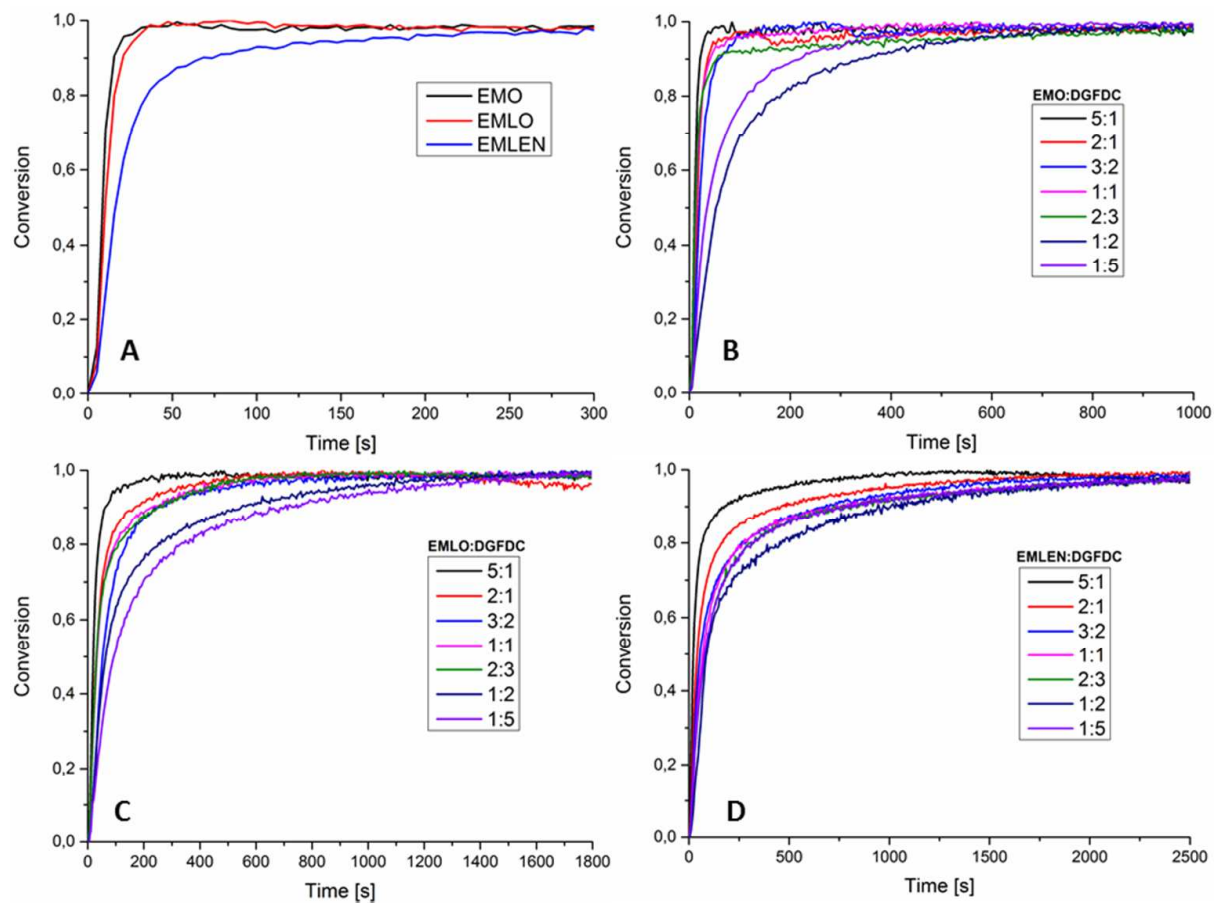

Figure 3: RT-FTIR measurements A: pure monomers; B: EMO-DGFDC; C: EMLO-DGFDC and D: EMLEN-DGFDC. In all cases following the formation of ether bonds at $1050-1100 \mathrm{~cm}^{-1}$

From the RT-FTIR results some pseudo-kinetic parameters could be determined. The main obstacle using this measurement was the lack of clearly isolated peaks for either the epoxides or the ethers. Therefore all results are relative between initial and final states of the curing system meaning $100 \%$ conversion correlates to point in time when the reaction stalls and no change in the traces from the ether region were observed. From these results it was possible to determine initial rates in $\% / \mathrm{s}$, initiation time as well as the time elapsed until no change occurred. All these values are summed in Table 1. For all EMX-DGFDC systems maximal rate and initiation time occurred within the first few scans (0-15 seconds), making the obtained values highly unprecise with the current resolution. This however still proves the efficiency of the applied polymerization method on this system with almost no initiation phase affecting the curing reaction. The measurements of maximal reaction rates showed the general trend of highest rates present at lower concentration of DGFDC as expected. Experiments with feeds containing only pure EMX monomers were also carried out in general showing that both EMO and EMLO were faster than EMLEN. However, DGFDC in its pure form had much slower reaction rates than the EMX monomers. The RT-FTIR traces for pure DGFDC showed that the ether region never levelled of most likely due to vitrification effect hence, the data was not comparable to data from pure EMX monomers. The respective order of the pure 
monomer reaction rates being EMO $>$ EMLO $>$ EMLEN $>>$ DGFDC, corroborating the trends observed by DSC (Figure 2A).

From the data presented in Table 1 no clear correlation of kinetic parameters to stoichiometry of feed could be observed except for the general trend of higher conversion times in EMLO and EMLEN systems when increasing the amount of DGFDC. It was expected that increased amounts of DGFDC would cause a direct correlation to decreasing reaction rate, assuming the free movement of the molecules (e.g. in a solution). However, the different molecular structures of the monomers the overall macromolecular dynamics of the bulk changes significantly when adjusting the stoichiometric ratios. Therefore, direct kinetic correlations were not observed.

In order to cure mixtures of EMX-DGFDC using UV-light some heating had to be applied. Though all EMX monomers are liquids, a DSC analysis of pure DGFDC revealed a melting point of $83{ }^{\circ} \mathrm{C}$, which was gradually lowered in mixtures with EMX monomers. Therefore all curing reactions for RT-FTIR experiments were carried out at $85{ }^{\circ} \mathrm{C}$ in order to keep the feed liquid. To evaluate the effect of the stoichiometry of the feed mixture curing reactions were carried out with DGFDC and each of the three EMX monomers in various epoxy molar ratios, namely EMX:DGFDC ratios of 5:1, 2:1, 3:2, 1:1, 2:3, 1:2 and 1:5 (Table 1). All systems were cured using 2 wt. \% of the UVAcure 1600 initiator. 
Table 1: The different monomer mixtures studied and their respective Tg obtained from DSC. The table also shows results from the RT-FTIR measurements

The products of the RT-FTIR UV-curing reactions were all analyzed using DSC, giving their respective Tg presented in Table 1. It was observed that all thermosets containing EMO-DGFDC yielded products with $\mathrm{Tg}$ below $-50{ }^{\circ} \mathrm{C}$ and was undetectable by the applied instrument. Due to the low Tg's the EMO-DGFDC system were deemed not suitable for DMTA analysis. DSC analyses of the EMLO-DGFDC and EMLEN-DGFDC system however showed varied Tg's in ranges of $-25{ }^{\circ} \mathrm{C}$ to $70{ }^{\circ} \mathrm{C}$, with increases corresponding to the increase in the amount of DGFDC (Figure 4). It 
should also be noted that all samples were fully cured since no post-curing was seen on the first DSC scan (Figure S29-31).

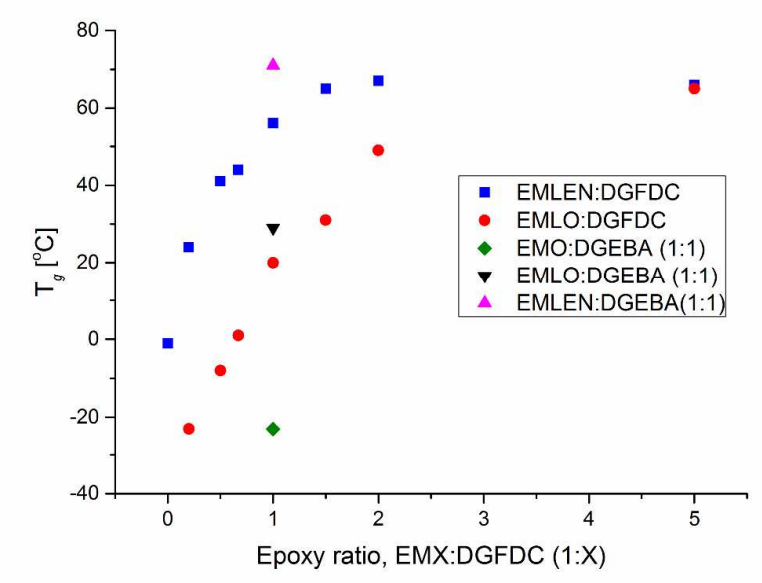

Figure 4: Tg's of the different thermoset systems EMLO-DGFDC and EMLEN-DGFDC determined by DSC. The Tg increases with increasing amount of DGFDC in both thermoset systems. DGEBA thermosets with EMX (1:1) equivalents yielding slightly higher $\operatorname{Tg}$ 's

Curing of only pure monomers were also carried out for the 4 applied reagents. Here only a glass transition of cross-linked EMLEN could be observed (following the trend in Tg's of the mixed systems). However, the Tg of cross-linked EMO and EMLO could not be observed most likely due to these temperature being below $-50{ }^{\circ} \mathrm{C}$ and therefore below the detection limit of the applied instrument. Cured DGFDC on the other hand yielded an irregular DSC curve, which hinted that the system could not cross-link properly. RT-FTIR experiments confirmed that the reaction of pure DGFDC was too slow to finish within the time window of the reaction. In order to evaluate the usability of DGFDC as a replacement for petrol-based monomers, a comparison to the widely used diglycidyl ether of bisphenol-A (DGEBA) was made. This was done by curing 1:1 epoxy molar ratio systems with the three EMX monomers (Table 1 Entry 26-28). These results showed comparable results with DGEBA system yielding Tg's of $9^{\circ} \mathrm{C}$ and $15^{\circ} \mathrm{C}$ higher than their DGFDC analogues for EMLO and EMLEN systems respectively. This increased temperature most likely stems from DGEBA containing two aromatic rings compared to the furan in DGFDC thus providing more rigidity to the system.

\section{Structure-Property relationship of the final thermosets}

In order to understand the influence of the thermo-mechanical behavior of the cured EMX-DGFDC systems, films for DMTA were made. Figure 5 shows the DMTA results. 
The results strengthen the hypothesis that the reaction between EMX-DGFDC leads to a crosslinked network. This can be observed in Figure 5A and $\mathrm{C}$ which shows that the rubbery plateau showed no flow behavior in any case. The difference in cross-linking density is clearly seen as an increase in modulus in the rubbery region. Increased amount of DGFDC as well as increased functionality of the fatty methyl ester both leads to increased cross-linking density. The glassy region however, showed small differences in the value of storage modulus (E') ranging from 1.0 2.7 $\mathrm{GPa}\left(-50^{\circ} \mathrm{C}\right)$. The highest value was obtained from the sample with most DGFDC (1:5 EMLO:DGFDC) which is comparable to common commercial plastics such as PET analyzed by DMTA. ${ }^{37}$
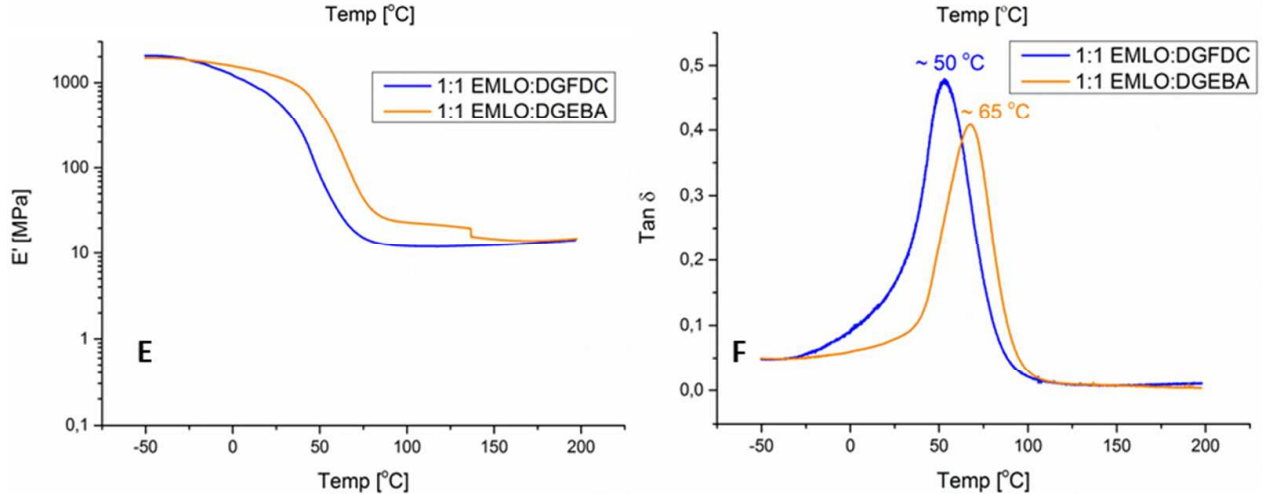

Figure 5: DMTA measurements on photo-cured thermosets A-B shows the EMLO-DGFDC system and C-D shows comparison between $F M L O$ and EMLEN thermosets and E-F shows the comparison between DGFDC and DGEBA thermosets.
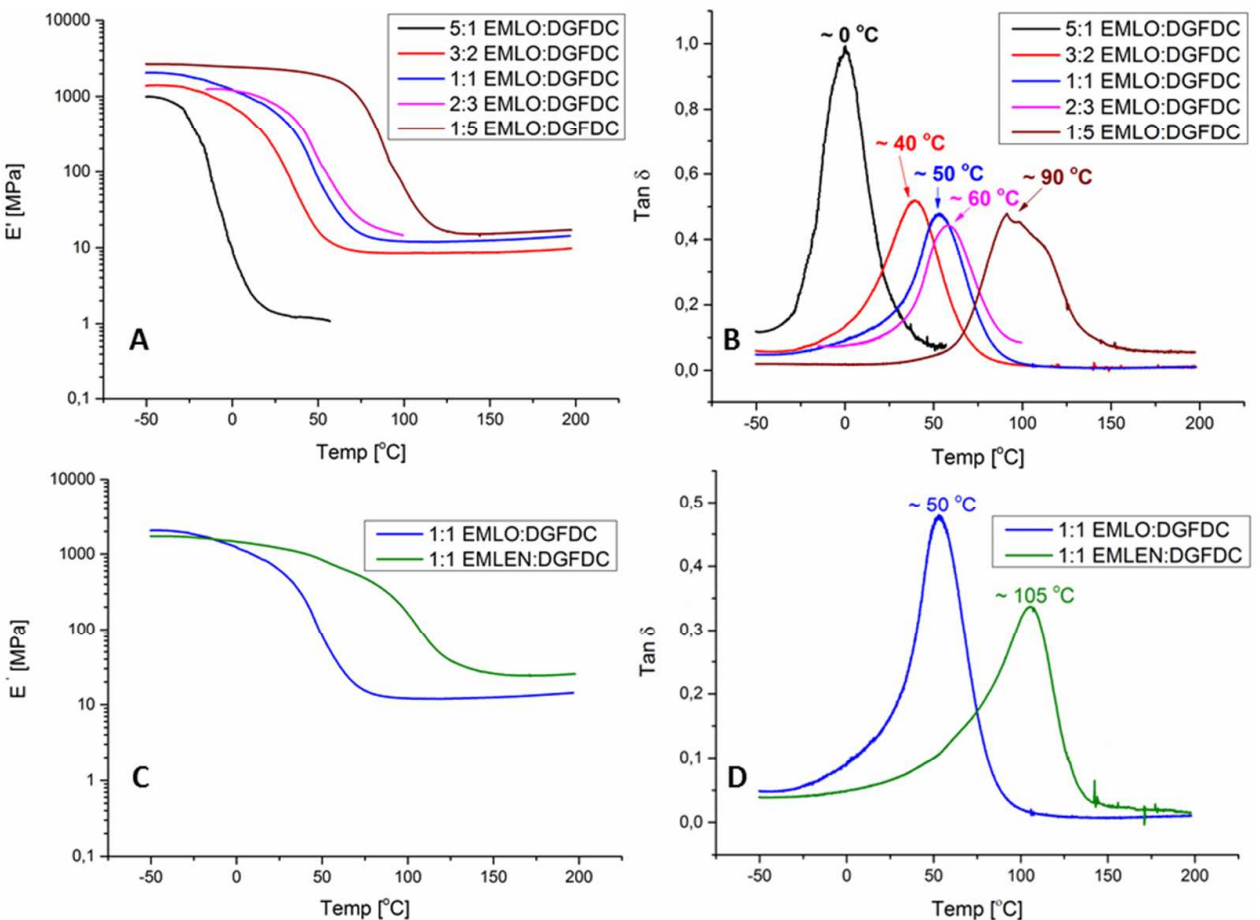
The Tg can also be detected by DMTA however, this transition usually shows higher values than $\mathrm{Tg}$ measured by DSC due to frequency effects. ${ }^{38}$ The Tg results from DMTA showed similar trend to the DSC results. This was the expected results due to the increased amount of rigidity stemming from the furan rings of DGFDC. Furthermore, only one Tg was observed in all EMLO-DGFDC monomer ratios indicating that the reaction between EMLO and DGFDC is not phase separated.

The different epoxy fatty methyl esters had a clear impact on the Tg. Both DMTA (Figure 5C-D) and DSC (Figure 4) results showed that EMLEN-DGFDC system exhibited higher Tg's compared to the corresponding EMLO system. This may be attributed to the amount of linear aliphatic chainends in the cross-linked network. The chain-end of EMLO is based on 5 carbon atoms while the EMLEN only have 2 carbon atoms. Longer chain-ends gave rise to higher degree of movement in the network which in turn resulted in a lower Tg observed (1:1 EMLO:DGFDC) and vice versa. It was also observed that an increased epoxy functionality provide a broader $\mathrm{Tg}$ i.e. a less homogeneous thermoset.

Moreover, thermosets containing EMLO and DGEBA was also made and analyzed with DMTA, Figure 5E-F and Figure S32-33. The data shows that similar trend to the results obtained from DSC, a higher Tg was obtained when using DGEBA instead of DGFDC. As aforementioned, DGEBA contains two aromatic rings which could be one reason for the increase in Tg. In addition, higher cross-linking degree was also obtained for the DGEBA system.

\section{Conclusions}

In the pursuit of utilizing bio-feedstocks as building blocks in polymers the application area of FDCA-based monomers has been extended into epoxy thermosets. In this study we aimed to address the influence of stoichiometry ratios on structure-property relationship. The study shows that it was possible to make thermosets by combining the diglycidyl ester of FDCA (DGFDC) with free epoxidized fatty methyl esters (EMX) retrieved from epoxidized linseed oil. The combination of the bio-based monomers showed that it was possible to have structure-property control due to the vastly different attributes of the monomers. EMX monomers provided flexible, hydrophobic structures and the furans of the DGFDC provided rigidity and mechanical stability. Moreover, it was also shown that UV-curing of the pure DGFDC showed very slow reaction speed. However, the reaction speed was significantly increased when DGFDC was mixed with any of the fatty acids. The thermo-mechanical properties was also assessed which showed that the bio-based DGFDC had promising results in comparison to the commercially available and petrol-based diglycidyl ether of 
bisphenol-A (DGEBA) regarding Tg properties. In addition, the storage modulus was in the range of $1.0-2.7 \mathrm{GPa}$ which is comparable to common plastics such as PET.

\section{Supporting Information}

NMR and FTIR spectra of monomers DAFDC, DGFDC, EMO, EMLO and EMLEN; Reactive DSC scans and Borchardt and Daniels kinetics of pure monomers and EMX-DGFDC systems; DSC of UV-cured thermosets from EMX-DGFDC and EMX-DGEBA; DMTA of EMLO/EMLENDGFDC and EMLO-DGEBA thermosets.

\section{Corresponding Author}

Correspondence to: Mats Johansson (E-mail: matskg@,kth.se)

KTH Royal Institute of Technology, Department of Fibre and Polymer Technology, Division of Coating Technology, SE-100 44 Stockholm, Sweden.

\section{Author Contributions}

All authors have written the manuscript and given approval of the final version of the manuscript.

\section{Acknowledgements}

The authors would like to acknowledge the Swedish research council, FORMAS (Grant number 211-2013-70) and Technical University of Denmark, Augustinus Fonden and Otto Mønsteds Fond for financial support.

\section{References}

(1) Andrady, A. L. Plastics and the Environment; John Wiley \& Sons, 2003.

(2) Werpy, T.; Petersen, G. Top Value Added Chemicals from Biomass Volume I - Results of Screening for Potential Candidates from Sugars and Synthesis Gas Top Value Added Chemicals From Biomass Volume I : Results of Screening for Potential Candidates. U.S. Dep. Energy 2004, 1 DOI: 10.2172/15008859.

(3) Belgacem, M. N.; Gandini, A. Monomers, Polymers and Composites from Renewable Resources; Elsevier: Oxford, 2008.

(4) Montero de Espinosa, L.; Meier, M. A. R. Plant oils: The perfect renewable resource for polymer science?! Eur. Polym. J. 2011, 47 (5), 837-852 DOI: 10.1016/j.eurpolymj.2010.11.020.

(5) Meier, M. A. R.; Metzger, J. O.; Schubert, U. S. Plant oil renewable resources as green alternatives in polymer science. Chem. Soc. Rev. 2007, 36 (11), 1788 DOI: $10.1039 / b 703294 c$. 
(6) Kienle, R. H.; Hovey, A. G. The polyhydric alcohol-polybasic acid reaction. I. Glycerolphthalic anhydride. J. Am. Chem. Soc. 1929, 51 (2), 509-519.

(7) Kienle, R. H.; Ferguson, C. S. Alkyd resins as film-forming materials. Ind. Eng. Chem. 1929, $21(4), 349-352$.

(8) Stenberg, C.; Svensson, M.; Johansson, M. A study of the drying of linseed oils with different fatty acid patterns using RTIR-spectroscopy and chemiluminescence (CL). Ind. Crops Prod. 2005, 21 (2), 263-272 DOI: 10.1016/j.indcrop.2004.04.002.

(9) Gall, R. J.; Greenspan, F. P. A modified peracid process for making epoxy compounds from unsaturated fatty acid esters. Ind. Eng. Chem. 1955, 47 (1), 147-148 DOI: 10.1021/ie50541a045.

(10) Pan, X.; Sengupta, P.; Webster, D. C. High biobased content epoxy-anhydride thermosets from epoxidized sucrose esters of fatty acids. Biomacromolecules 2011, 12 (6), 2416-2428 DOI: $10.1021 / \mathrm{bm} 200549 \mathrm{c}$.

(11) Pan, X.; Webster, D. C. New Biobased High Functionality Polyols and Their Use in Polyurethane Coatings. ChemSusChem 2012, 5 (2), 419-429 DOI: 10.1002/cssc.201100415.

(12) Gunstone, F. D. Fatty Acids. Part II. The nature of the oxygenetad acid present in Vernonia anthelminitca (Willd.) seed oil. J. Chem. Soc. 1954, 1611-1616.

(13) Muuse, B. G.; Petrus Cuperus, F.; Derksen, J. T. P. Composition and physical properties of oils from new oilseed crops. Ind. Crops Prod. 1992, 1 (1), 57-65 DOI: 10.1016/09266690(92)90046-X.

(14) Krasutsky, P. A. Birch bark research and development. Nat. Prod. Rep. 2006, 23 (6), 919 DOI: $10.1039 / \mathrm{b} 606816 \mathrm{~b}$.

(15) Tomasi, P.; Wang, H.; Lohrey, G. T.; Park, S.; Dyer, J. M.; Jenks, M. A.; Abdel-Haleem, H. Characterization of leaf cuticular waxes and cutin monomers of Camelina sativa and closelyrelated Camelina species. Ind. Crops Prod. 2017, 98, 130-138 DOI: 10.1016/j.indcrop.2017.01.030.

(16) Tsubaki, S.; Sakumoto, S.; Uemura, N.; Azuma, J. I. Compositional analysis of leaf cuticular membranes isolated from tea plants (Camellia sinensis L.). Food Chem. 2013, 138 (1), 286290 DOI: 10.1016/j.foodchem.2012.10.116.

(17) Boisen, A.; Christensen, T. B.; Fu, W.; Gorbanev, Y. Y.; Hansen, T. S.; Jensen, J. S.; Klitgaard, S. K.; Pedersen, S.; Riisager, A.; Ståhlberg, T.; et al. Process integration for the conversion of glucose to 2,5-furandicarboxylic acid. Chem. Eng. Res. Des. 2009, 87 (9), 1318-1327 DOI: 10.1016/j.cherd.2009.06.010.

(18) Moreau, C.; Belgacem, M. N.; Gandini, A. Recent Catalytic Advances in the Chemistry of Substituted Furans from Carbohydrates and in the Ensuing Polymers. Top. Catal. 2004, 27 (1-4), 11-30 DOI: 10.1023/B:TOCA.0000013537.13540.0e.

(19) Eerhart, A. J. J. E.; Faaij, A. P. C.; Patel, M. K. Replacing fossil based PET with biobased PEF; process analysis, energy and GHG balance. Energy Environ. Sci. 2012, 5 (4), 64076422 DOI: $10.1039 / \mathrm{c} 2 \mathrm{ee} 02480 \mathrm{~b}$.

(20) Tomás, R. A. F.; Bordado, J. C. M.; Gomes, J. F. P. p-Xylene Oxidation to Terephthalic 
Acid : A Literature Review Oriented toward Process Optimization and Development. Chem. Rev. 2013, 113, 7421-7469 DOI: 10.1021/cr300298j.

(21) Larsen, D. B.; Sønderbæk-Jørgensen, R.; Duus, J.; Daugaard, A. E. Investigation of curing rates of bio-based thiol-ene films from diallyl 2,5- furandicaboxylate. Eur. Polym. J. 2018, 102 (November 2017), 1-8 DOI: 10.1017/S0950268817001236.

(22) Deng, J.; Liu, X.; Li, C.; Jiang, Y.; Zhu, J. Synthesis and properties of a bio-based epoxy resin from 2,5-furandicarboxylic acid (FDCA). RSC Adv. 2015, 5 (21), 15930-15939 DOI: 10.1039/C5RA00242G.

(23) Burrows, A.; Holman, J.; Parsons, A.; Pilling, G.; Price, G. Chemistry3: introducing inorganic, organic and physical chemistry, 1st ed.; Oxford University Press: New York, 2009.

(24) Sangermano, M.; Vitale, A.; Dietliker, K. Photolatent amines producing a strong base as photocatalyst for the in-situ preparation of organic-inorganic hybrid coatings. Polymer (Guildf). 2014, 55 (7), 1628-1635 DOI: https://doi.org/10.1016/j.polymer.2014.02.045.

(25) Carioscia, J. A.; Stansbury, J. W.; Bowman, C. N. Evaluation and control of thiol-ene/thiolepoxy hybrid networks. Polymer (Guildf). 2007, 48 (6), 1526-1532 DOI: 10.1016/j.polymer.2007.01.044.

(26) Ashcroft, W. R.; Cantwell, W. J.; Chen, X. M.; Ellis, B.; Johari, G. P.; Jones, F. R.; Kausch, H. H.; Shaw, S. J. Chemistry and Technology of Epoxy Resins; 1993.

(27) Crivello, J. V.; Lam, J. H. W. Diaryliodonium Salts. A New Class of Photoinitiators for Cationic Polymerization. Macromolecules 1977, 10 (6), 1307-1315 DOI: 10.1021/ma60060a028.

(28) Crivello, J. V.; Lam, J. H. W. Photoinitiated cationic polymerization with triarylsulfonium salts. J. Polym. Sci. Part A Polym. Chem. 1996, 34 (16), 3231-3253 DOI: 10.1002/pola.1996.873.

(29) Michaudel, Q.; Kottisch, V.; Fors, B. P. Cationic Polymerization: From Photoinitiation to Photocontrol. Angew. Chemie - Int. Ed. 2017, 56 (33), 9670-9679 DOI: 10.1002/anie.201701425.

(30) Decker, C.; Nguyen Thi Viet, T.; Pham Thi, H. Photoinitiated cationic polymerization of epoxides. Polym. Int. 2001, 50 (9), 986-997.

(31) Crivello, J. V. Cationic polymerization - Iodonium and sulfonium salt photoinitiators. $A d v$. Polym. Sci. 1984, 62, 1-48 DOI: 10.1007/BFb0024033.

(32) Borchardt, H. J.; Daniels, F. The Application of Differential Thermal Analysis to the Study of Reaction Kinetics. J. Am. Chem. Soc. 1957, 79 (1), 41-46 DOI: 10.1021/ja01558a009.

(33) Designation: E2041-13. Estimating Kinetic Parameters by Differential Scanning Calorimeter Using the Borchardt and Daniels Method 1. Astm 2015, 14, 1-7 DOI: 10.1520/E204113E01.2.

(34) Nameer, S.; Johansson, M. Fully bio-based aliphatic thermoset polyesters via self-catalyzed self-condensation of multifunctional epoxy monomers directly extracted from natural sources. J. Coatings Technol. Res. 2017, 14 (4), 757-765 DOI: 10.1007/s11998-017-9920-y. 
(35) Kester, E. B.; Gaiser, C. J.; Lazar, M. E. Glycidyl esters of aliphatic acids. J. Org. Chem. 1943, 8 (6), 550-556 DOI: 10.1021/jo01194a010.

(36) Maerker, G.; Carmichael, J. F.; Port, W. S. Glycidyl Esters. I. Method of Preparation and Study of Some Reaction Variables. J. Org. Chem. 1961, 26 (8), 2681-2688 DOI: 10.1021/jo01066a018.

(37) Mouzakis, D. E.; Papke, N.; Wu, J. S.; Karger-Kocsis, J. Fracture toughness assessment of poly(ethylene terephthalate) blends with glycidyl methacrylate modified polyolefin elastomer using essential work of fracture method. J. Appl. Polym. Sci. 2001, 79 (5), 842-852 DOI: 10.1002/1097-4628(20010131)79:5<842::AID-APP90>3.0.CO;2-1.

(38) Nielsen, L. E. Mechanical properties of polymers and composites; CRC press: New York, 1994. 


\section{For Table of Contents Use Only}

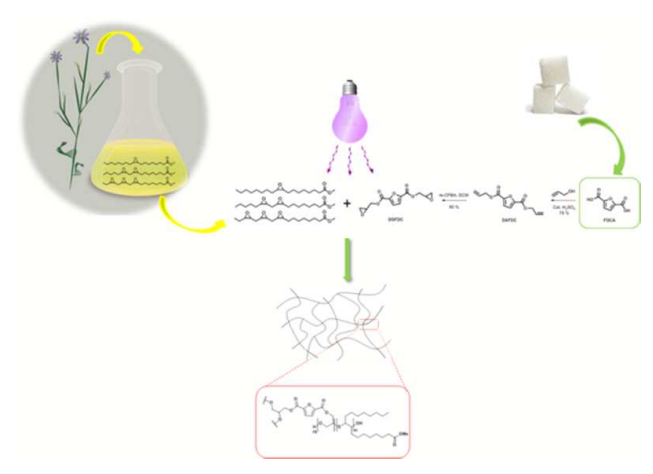

\section{Synopsis:}

This work utilizes renewable building blocks and radiation curing to form bio-based epoxy thermosets. 

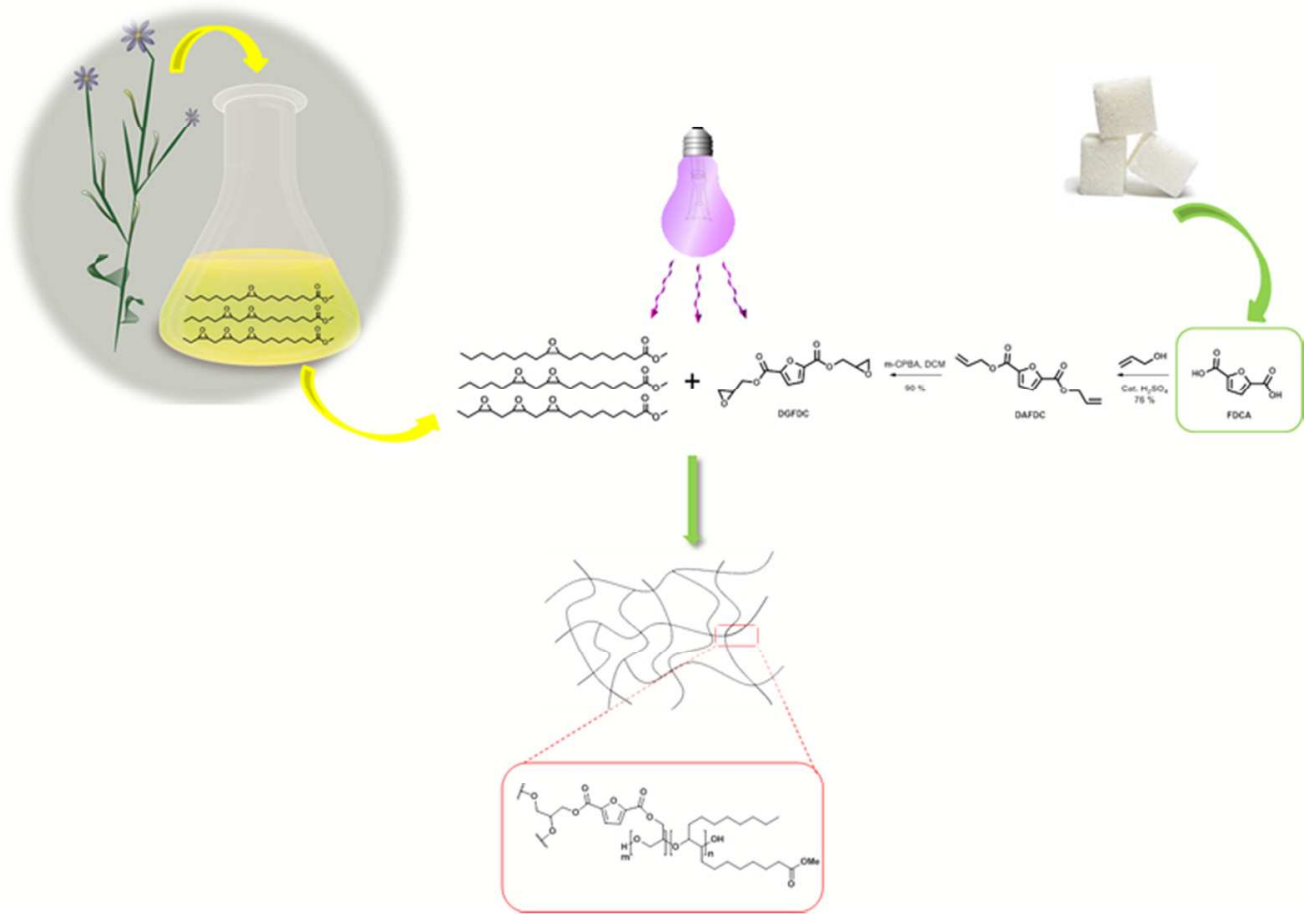

This work utilizes renewable building blocks and radiation curing to form bio-based epoxy thermosets $67 \times 47 \mathrm{~mm}(300 \times 300 \mathrm{DPI})$ 